Research

\title{
Brachial artery peak velocity variation to predict fluid responsiveness in mechanically ventilated patients
}

\author{
Manuel Ignacio Monge García, Anselmo Gil Cano and Juan Carlos Díaz Monrové
}

\author{
Servicio de Cuidados Críticos y Urgencias, Unidad de Investigación Experimental, Hospital del SAS Jerez, C/Circunvalación s/n, 11407, Jerez de la \\ Frontera, Spain \\ Corresponding author: Manuel Ignacio Monge García, ignaciomonge@gmail.com
}

Received: 22 May 2009 Revisions requested: 25 Jun 2009 Revisions received: 6 Jul 2009 Accepted: 3 Sep 2009 Published: 3 Sep 2009

Critical Care 2009, 13:R142 (doi:10.1186/cc8027)

This article is online at: http://ccforum.com/content/13/5/R142

(c) 2009 Monge García et al.; licensee BioMed Central Ltd.

This is an open access article distributed under the terms of the Creative Commons Attribution License (http://creativecommons.org/licenses/by/2.0), which permits unrestricted use, distribution, and reproduction in any medium, provided the original work is properly cited.

\begin{abstract}
Introduction Although several parameters have been proposed to predict the hemodynamic response to fluid expansion in critically ill patients, most of them are invasive or require the use of special monitoring devices. The aim of this study is to determine whether noninvasive evaluation of respiratory variation of brachial artery peak velocity flow measured using Doppler ultrasound could predict fluid responsiveness in mechanically ventilated patients.
\end{abstract}

Methods We conducted a prospective clinical research in a 17bed multidisciplinary ICU and included 38 mechanically ventilated patients for whom fluid administration was planned due to the presence of acute circulatory failure. Volume expansion (VE) was performed with $500 \mathrm{~mL}$ of a synthetic colloid. Patients were classified as responders if stroke volume index (SVi) increased $\geq 15 \%$ after VE. The respiratory variation in $V_{\text {peak }} \mathrm{brach}\left(\Delta \mathrm{Vpeak}_{\text {brach }}\right)$ was calculated as the difference between maximum and minimum values of $V_{\text {peak }}$ brach $_{\text {over a }}$ single respiratory cycle, divided by the mean of the two values and expressed as a percentage. Radial arterial pressure variation $\left(\triangle \mathrm{PP}_{\text {rad }}\right)$ and stroke volume variation measured using the FloTrac/Vigileo system $\left(\Delta \mathrm{SV}_{\text {Vigileo }}\right)$, were also calculated.

Results VE increased SVi by $\geq 15 \%$ in 19 patients (responders). At baseline, $\Delta \mathrm{Vpeak}_{\text {brach, }} \Delta \mathrm{PP}_{\text {rad }}$ and $\Delta \mathrm{SV}_{\text {Vigileo }}$ were significantly higher in responder than nonresponder patients [14 vs $8 \% ; 18$ vs. $5 \% ; 13$ vs $8 \% ; \mathrm{P}<0.0001$, respectively). A $\Delta$ Vpeak $_{\text {brach }}$ value $>10 \%$ predicted fluid responsiveness with a sensitivity of $74 \%$ and a specificity of $95 \%$. A $\Delta \mathrm{PP}_{\text {rad }}$ value $>10 \%$ and a $\Delta \mathrm{SV}_{\text {Vigileo }}>11 \%$ predicted volume responsiveness with a sensitivity of $95 \%$ and $79 \%$, and a specificity of $95 \%$ and $89 \%$, respectively.

Conclusions Respiratory variations in brachial artery peak velocity could be a feasible tool for the noninvasive assessment of fluid responsiveness in patients with mechanical ventilatory support and acute circulatory failure.

Trial Registration ClinicalTrials.gov ID: NCT00890071

\section{Introduction}

Traditional indices of cardiac preload, such as intracardiac pressures or telediastolic volumes, have been consistently surpassed by dynamic parameters to detect fluid responsiveness in critically ill patients $[1,2]$. The magnitude of cyclic changes in left ventricular (LV) stroke volume due to intermittent positive-pressure ventilation have been demonstrated to accurately reflect preload-dependence in mechanically ventilated patients [3]. So, the greater the respiratory changes in LV stroke volume, the greater the expected increase in stroke volume after fluid administration.

By increasing intrathoracic pressure and lung volume, mechanical insufflation raises both pleural and transpulmonary pressure, decreasing the pressure gradient for venous return and increasing right ventricular (RV) afterload. According to

$\Delta \mathrm{PP}_{\text {rad }}:$ radial artery pulse pressure variation; $\Delta \mathrm{SV}_{\text {Vigileo }}$ : stroke volume variation assessed using FloTrac/Vigileo system; $\Delta \mathrm{Vpeak}_{\text {brach }}:$ brachial artery

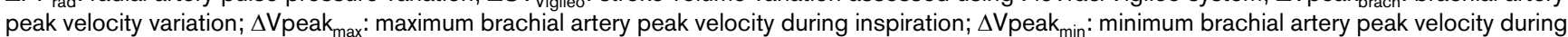
expiration; Cl: confidence interval; CO: cardiac output; CVP: central venous pressure; LV: left ventricle; PEEP: positive end-expiratory pressure; $\mathrm{PP}_{\max }$ : maximum pulse pressure determined during a single respiratory cycle; $\mathrm{PP}_{\min }$ : minimum pulse pressure determined during a single respiratory cycle; ROC: receiver operating characteristic; RV: right ventricle; $\mathrm{SV}_{\max }$ : maximum stroke volume; $\mathrm{SV}_{\text {mean }}:$ mean stroke volume; $\mathrm{SV}_{\text {min }}:$ minimum stroke volume; SVi: stroke volume index; VE: volume expansion. 
the Frank-Starling relationship, if both ventricles remain sensitive to changes in preload, RV stroke volume, and therefore LV preload, should decrease during positive-pressure inspiration, diminishing LV stroke volume after a few beats (normally during expiration). On the otherhand, if any of the ventricles are unaffected by cyclic variations of preload, LV stroke volume should be unaltered by swings in intrathoracic pressure. Therefore, the degree of respiratory variations in LV stroke volume could be used to reveal the susceptibility of the heart to changes in preload induced by mechanical insufflation [3].

In this regard, several surrogate measurements of LV stroke volume have been proposed to determine the preloaddependence status of a patient, such as pulse pressure variation [4], stroke volume variation [5] or aortic blood flow variation [6]. However, the acquisition of these parameters usually requires an invasive catheterization or a skilled echocardiographic evaluation to obtain an accurate interpretation of data, limiting their applicability because of the need for specialized training and equipment.

Recently, Brennan and colleagues [7], using a hand-carried Doppler ultrasound at the bedside, demonstrated that respira-

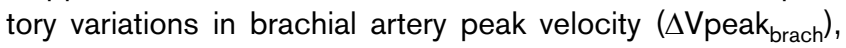
measured by clinicians with minimal ultrasound expertise, were closely correlated with radial artery pulse pressure variations $\left(\Delta P P_{\text {rad }}\right)$, a well-known parameter of fluid responsiveness. Moreover, a $\Delta \mathrm{Vpeak}_{\text {brach }}$ value of $16 \%$ or more was highly predictive of a $\Delta \mathrm{PP}_{\text {rad }}$ of $13 \%$ or more (the usual $\Delta \mathrm{PP}_{\text {rad }}$ threshold value for discrimination between fluid responder and nonresponder patients), so $\Delta V_{\text {peak }}$ brach $_{\text {could be used as a }}$ noninvasive surrogate of $L V$ stroke volume variation for assessing preload dependence in patients receiving controlled mechanical ventilation. However, the predictive value of this indicator was not tested performing a volume challenge and checking the effects on cardiac output (CO) or stroke volume. Thus, although promising, further studies are required before validating this parameter and recommending it for its clinical use [8].

Therefore, we designed the current study to confirm the predictive value of the $\Delta \mathrm{Vpeak}_{\mathrm{brach}}$ for predicting fluid responsiveness in mechanically ventilated patients with acute circulatory failure.

\section{Materials and methods}

This study was approved by the Institutional Ethics Committee of the Jerez Hospital of the Andalusian Health Service and endorsed by the Scientific Committee of the Spanish Society of Intensive Care, Critical and Coronary Units. Written informed consent was obtained from each patient's next of kin.

\section{Patients}

The inclusion criteria were patients with controlled mechanical ventilation, equipped with an indwelling radial artery catheter and for whom the decision to give fluids was taken due to the presence of one or more clinical signs of acute circulatory failure, defined as a systolic blood pressure of less than 90 $\mathrm{mmHg}$ (or a decrease of more than $50 \mathrm{mmHg}$ in previously hypertensive patients) or the need for vasopressor drugs; the presence of oliguria (urine output $<0.5 \mathrm{ml} / \mathrm{kg} / \mathrm{min}$ for at least two hours); the presence of tachycardia; a delayed capillary refilling; or the presence of skin mottling. Contraindication for the volume administration was based on the evidence of fluid overload and/or hydrostatic pulmonary edema. Patients with unstable cardiac rhythm were also excluded.

\section{Arterial pulse pressure variation}

Radial arterial pressure was recorded online on a laptop computer at a sampling rate of $300 \mathrm{~Hz}$ using proprietary dataacquisition software (S/5 Collect software, version 4.0; DatexOhmeda, Helsinki, Finland) for further off-line analysis (QtiPlot software, version 0.9.7.6 [9].

$\Delta \mathrm{PP}_{\text {rad }}$ was defined according to the formula:

$\left.\Delta \mathrm{PP}_{\mathrm{rad}}(\%)=100 \times\left(\mathrm{PP}_{\mathrm{max}}-\mathrm{PP}_{\mathrm{m} \dot{\mathrm{n}}}\right) /\left(\left(\mathrm{PP}_{\mathrm{max}}+\mathrm{PP}_{\mathrm{min}}\right) / 2\right)\right)$

where $\mathrm{PP}_{\max }$ and $\mathrm{PP}_{\text {min }}$ are the maximum and minimum pulse pressures determined during a single respiratory cycle, respectively [10]. The average of three consecutive determinations was used to calculate $\Delta \mathrm{PP}_{\text {rad }}$ for statistical analysis.

\section{Respiratory variation in brachial artery blood velocity}

The brachial artery blood velocity signal was obtained using a Doppler ultrasound scanner (Vivid 3, General Electric, Waukesha, WI, USA), equipped with a 4 to $10 \mathrm{MHz}$ flat linear array transducer. With the patient in the supine position, the transducer was placed over a slightly abducted arm, opposite to the indwelling radial artery catheter and 5 to $10 \mathrm{~cm}$ above the antecubital fossa. After confirmed correct placement and artery pulse quality by Doppler ultrasound, the transducer was rotated to acquire the transversal image of the artery. Angle Doppler was adjusted to ensure a less than $60^{\circ}$ angle for the accurate determination of Doppler shift and blood flow velocity. The velocity waveform was recorded from the midstream of the vessel lumen and the sample volume was adjusted to cover the center of the arterial vessel, in order to obtain a clear Doppler blood velocity trace. Brachial flow velocity was registered simultaneously to the radial arterial pressure for at least one minute.

The $\Delta$ Vpeak $_{\text {brach }}$ was calculated on-line using built-in software as:

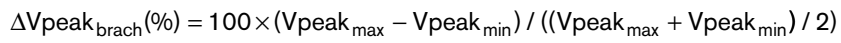

where $\mathrm{Vpeak}_{\max }$ and $\mathrm{Vpeak}_{\min }$ are the maximum and the minimum peak systolic velocities during a respiratory cycle, 
respectively. The mean values of the three consecutive determinations were used for statistical analysis.

The intraobserver reproducibility was determined for $\Delta$ Vpeakbrach measurements using Bland-Altman test analysis in all target patients over a one-minute period, and described as mean bias \pm limits of agreements.

\section{Cardiac output and stroke volume variation measurements}

A FloTrac sensor (Edwards Lifesciences LLC, Irvine, CA, USA) was connected to the arterial line and attached to the Vigileo monitor, software version 1.10 (Edwards Lifesciences LLC, Irvine, CA, USA). Briefly, the CO was calculated from the real-time analysis of the arterial waveform over a period of 20 seconds at a sample rate of $100 \mathrm{~Hz}$ without prior external calibration, using a proprietary algorithm based on the relation between the arterial pulse pressure and stroke volume. Arterial compliance and vascular resistance contribution was estimated every minute based on individual patient demographic data (age, gender, body weight and height) and the arterial waveform analysis, respectively. Stroke volume variation ( $\Delta S \mathrm{SV}$ Vigileo) was assessed by the system as follows:

$$
\Delta S C_{\text {Vigileo }}(\%)=100 \times\left(S_{\text {max }}-S_{\text {min }}\right) / S V_{\text {mean }}
$$

A time interval of 20 seconds was used by the algorithm to calculate $\mathrm{SV}_{\text {mean }}$ and $\Delta \mathrm{SV}_{\text {Vigileo }}[11]$.

After zeroing the system against atmosphere, the arterial waveform signal fidelity was checked using the square wave test and hemodynamic measurements were initiated. $\mathrm{CO}$, stroke volume and $\Delta \mathrm{SV}_{\text {Vigileo }}$ values were obtained by an independent physician and averaged as the mean of three consecutive measurements. The Doppler operator was unaware of the Vigileo monitor measurements.

\section{Study protocol}

All the patients were ventilated in controlled-volume mode (Puritan Bennett 840 ventilator, Tyco, Mansfield, MA, USA) and temporally paralyzed (vecuronium bromide $0,1 \mathrm{mg} / \mathrm{Kg}$ ) if spontaneous inspiratory efforts were detected on the airway pressure curve displayed on the respiratory monitor. Supportive therapies, ventilatory settings and vasopressor therapy were kept unchanged throughout the study time. A first set of hemodynamic measurements was obtained at baseline and after volume expansion (VE), consisting of $500 \mathrm{ml}$ of synthetic colloid (Voluven ${ }^{\circledR}$, hydroxyethylstarch 6\%; Fresenius, Bad Homburg, Germany) infused over 30 minutes.

\section{Statistical analysis}

Non-parametric tests were applied as data were not normally distributed. Results are expressed as median and interquartile range (25th to $75^{\text {th }}$ percentiles). Patients were classified according to stroke volume index (SVi) increase after VE in responders $(\geq 15 \%)$ and nonresponders $(<15 \%)$, respectively [10]. The effects of VE on hemodynamic parameters were assessed using the Wilcoxon rank sum test. Differences between responder and nonresponder patients were established by the Mann-Whitney $U$ test. The rate of vasopressor treatment was compared between responder and nonresponder patients using the chi-squared test. The relations between variables were analyzed using a linear regression method. The area under the receiver operating characteristic (ROC) curves for $\Delta \mathrm{Vpeak}_{\text {brach }}, \Delta \mathrm{PP}_{\text {rad }}, \Delta \mathrm{SV}_{\text {Vigileo }}$ and central venous pressure (CVP) according to fluid expansion response were calculated and compared using the Hanley-McNeil test. ROC curves are presented as area \pm standard error $(95 \%$ confidence interval (Cl)). A $P$ value less than 0.05 was considered statistically significant. Statistical analyses were performed using MedCalc for Windows, version 10.3.4.0 (MedCalc Software, Mariakerke, Belgium).

\section{Results}

Thirty-eight patients were included in the study, 19 of them with an increased SVi of $15 \%$ or higher (responders). The main characteristics of the studied population are summarized in Table 1. The vasoactive rate was not different between

Table 1

Characteristics and demographics data of $t$ population $(n=38)$

\begin{tabular}{|c|c|}
\hline Age (years) & 54.5 (45 to 69$)$ \\
\hline Gender (M/F) & $19 / 19$ \\
\hline Body surface area $\left(m^{2}\right)$ & 1.90 (1.73 to 2.03$)$ \\
\hline Death, $n(\%)$ & $11(29 \%)$ \\
\hline ICU stay before inclusion (days) & 1 ( 1 to 2$)$ \\
\hline \multicolumn{2}{|l|}{ Ventilator settings } \\
\hline Tidal volume, $\mathrm{mL} / \mathrm{Kg}$ ideal body weight & 9 (8 to 10$)$ \\
\hline Respiratory rate, breaths/min & 20 (18 to 20$)$ \\
\hline Total PEEP, $\mathrm{cm} \mathrm{H}_{2} \mathrm{O}$ & 6 (4 to 6$)$ \\
\hline $\mathrm{FiO}_{2}, \%$ & $63(50$ to 80$)$ \\
\hline $\mathrm{SaO}_{2}, \%$ & 98.5 (95 to 99$)$ \\
\hline Norepinephrine, $n$; dose $(\mu / \mathrm{kg} / \mathrm{min})$ & $17 ; 0.52$ (0.38 to 0.9$)$ \\
\hline Dobutamine, $n$; dose $(\mu \mathrm{g} / \mathrm{kg} / \mathrm{min})$ & $4 ; 7.11(4.89$ to 11.04$)$ \\
\hline \multicolumn{2}{|l|}{ Sepsis, $n$ (\%) } \\
\hline Abdominal & $11(29 \%)$ \\
\hline Pulmonary & $3(8 \%)$ \\
\hline Neurological & $3(8 \%)$ \\
\hline Urological & $2(5 \%)$ \\
\hline Skin and soft tissues & $1(3 \%)$ \\
\hline
\end{tabular}

Values are expressed as absolute numbers or median with interquartile range $\left(25^{\text {th }}\right.$ to $75^{\text {th }}$ percentiles). F: female; $\mathrm{FiO}$ : inspired oxygen fraction; ICU: intensive care unit; M: male; PEEP: positive end-expiratory pressure; $\mathrm{SaO}_{2}$ : arterial oxygen saturation. 
responders and nonresponders. Neither tidal volume nor positive end-expiratory pressure (PEEP) was significantly different between both groups. Volume expansion was performed according to the presence of hypotension $(n=19 ; 50 \%)$, oliguria $(n=29 ; 76 \%)$, tachycardia $(n=18 ; 47 \%)$, delayed capillary refilling $(n=7 ; 18 \%)$ and mottled skin $(n=2 ; 5 \%)$. The intraobserver variability in $\Delta \mathrm{V}_{\text {peak }} \mathrm{b}_{\text {brach }}$ measurement was $-1 \pm$ 6.68 .

\section{Hemodynamic response to volume expansion}

Hemodynamic parameters before and after VE are displayed in Table 2. In the whole population, VE induced a significant percentage gain in mean arterial pressure of $9.1 \%$ (3.3 to $19 \%)$, cardiac index by $10 \%$ (2.1 to $20.1 \%)$, SVi by $29 \%$ (20.4 to $37.5 \%$ ) and CVP by $60 \%$ (28.5 to $72 \%$ ).

\section{Effects of VE on dynamic parameters of preload}

The effects of VE on dynamic parameters of preload are summarized in Table 3. Individual values are displayed in Figure 1. At baseline, dynamic parameters did not differ between patients treated with norepinephrine and without vasopressor support. Volume loading was associated with a significant decrease in $\Delta \mathrm{Vpeak}_{\text {brach }}(3 \%, 1$ to $6 ; P<0.0001), \Delta \mathrm{PP}_{\text {rad }}(4 \%$, 2 to $11 ; P<0.0001)$ and $\Delta \mathrm{SV}_{\text {Vigileo }}(3 \%, 1$ to $6 ; P<0.0001)$ in both groups. An example of effects of $V E$ in $\Delta V_{p e a k_{b r a c h}}$ in one responder patient and other nonresponder is shown in Figure 2.

Table 2

\section{Effects of volume expansion in hemodynamic parameters}

\begin{tabular}{|c|c|c|}
\hline & Pre VE & Post VE \\
\hline \multicolumn{3}{|l|}{$\mathrm{Cl}, \mathrm{L} / \mathrm{min} / \mathrm{m}^{2}$} \\
\hline Responders & 2.85 (2.64 to 3.34$)$ & $3.74(2.93 \text { to } 4.14)^{\star \star}$ \\
\hline Nonresponders & 2.76 (2.34 to 4.54$)$ & $2.76(2.53 \text { to } 4.57)^{\star}$ \\
\hline \multicolumn{3}{|l|}{$\mathrm{HR}$, beats/min } \\
\hline Responders & 102 (90 to 118$) \dagger$ & $91(82 \text { to } 109)^{*}$ \\
\hline Nonresponders & 75 (65 to 101$)$ & 77 (68 to 100$)$ \\
\hline \multicolumn{3}{|l|}{$\mathrm{SVi}, m L / m^{2}$} \\
\hline Responders & $30.4(23.9$ to 39$) \dagger$ & $37.9(32.1$ to 50.6$)$ *** \\
\hline Nonresponders & 37.8 (30.7 to 47.1$)$ & 36.9 (32 to 49$)$ \\
\hline \multicolumn{3}{|l|}{ MAP, $m m H g$} \\
\hline Responders & 72 (62 to 78 ) & $81(65 \text { to } 89)^{\star \star}$ \\
\hline Nonresponders & 78 (69 to 86$)$ & $91(76 \text { to } 100)^{\star \star}$ \\
\hline \multicolumn{3}{|l|}{$\mathrm{SAP}, m m H g$} \\
\hline Responders & $102(80$ to 115$) \dagger$ & $120(96 \text { to } 139)^{\star \star}$ \\
\hline Nonresponders & 126 (106 to 141$)$ & $141(115 \text { to } 158)^{\star \star \star}$ \\
\hline \multicolumn{3}{|l|}{ DAP, $m m H g$} \\
\hline Responders & 55 (48 to 59 ) & $58(50 \text { to } 64)^{*}$ \\
\hline Nonresponders & 52 (45 to 63 ) & $60(51 \text { to } 73)^{*}$ \\
\hline \multicolumn{3}{|c|}{ TSVRi, dyn $\cdot s \cdot \mathrm{cm}^{-5} \cdot \mathrm{m}^{2}$} \\
\hline Responders & 1768 (1478 to 2066$)$ & $1662(1333 \text { to } 1744)^{*}$ \\
\hline Nonresponders & 1959 (1258 to 2271$)$ & 1930 (1236 to 2582$)$ \\
\hline \multicolumn{3}{|l|}{ CVP, $m m H g$} \\
\hline Responders & 7 (4 to 10$)$ & $10(7$ to 12$) \dagger^{\star \star \star}$ \\
\hline Nonresponders & $8(6$ to 11$)$ & $13(11 \text { to } 16)^{\star \star \star}$ \\
\hline
\end{tabular}

Data are expressed as median with interquartile range $\left(25^{\text {th }}\right.$ to $75^{\text {th }}$ percentiles). ${ }^{*} P<0.05,{ }^{\star \star} P<0.001,{ }^{* \star *} P<0.0001$ post VE vs pre VE; $+P$ $<0.05$ responders vs nonresponders.

$\mathrm{Cl}$ : cardiac index; CVP: central venous pressure; DAP: diastolic arterial pressure; HR: heart rate; MAP: mean arterial pressure; SAP: systolic arterial pressure; Svi: stroke volume index; TSVRi: total systemic vascular resistance index; VE: volume expansion. 
Figure 1

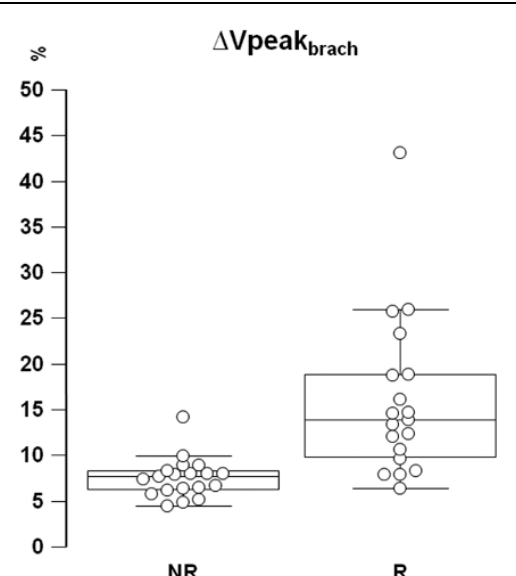

NR

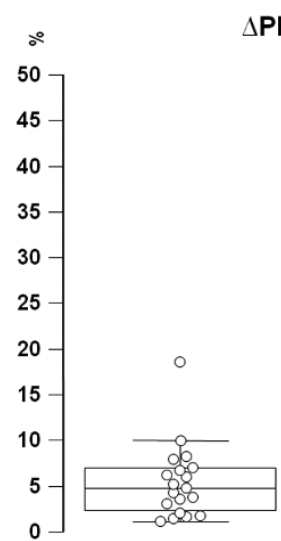

NR
$\Delta \mathrm{PP}_{\text {rad }}$

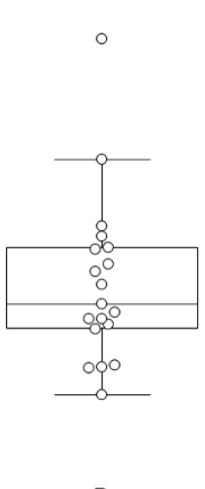

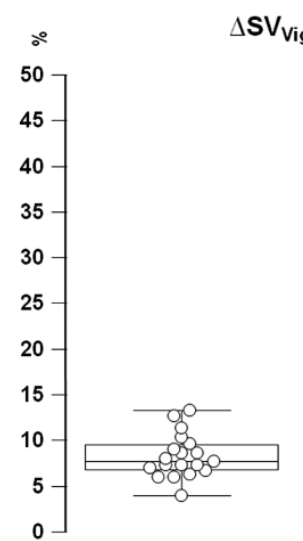

NR

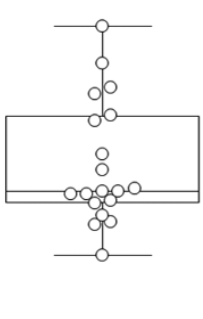

$\mathbf{R}$

Comparison of different dynamic indices of preload. Box-and-whisker plots and individual values (open circles) of respiratory variations of brachial peak velocity $\left(\Delta \mathrm{Vpea}_{\mathrm{brach}}\right)$, radial arterial pulse pressure variation $\left(\Delta \mathrm{PP}_{\mathrm{rad}}\right)$ and stroke volume variation measured using the FloTrac/Vigileo monitoring system $\left(\Delta S V_{\text {Vigileo }}\right)$ before volume expansion $(\mathrm{VE})$, in responder $(\mathrm{R}$, stroke volume index $(\mathrm{SVi}) \geq 15 \%$ after VE) and nonresponder $(\mathrm{NR}, \mathrm{SVi}<15 \%$ after VE) patients. The central box represents the values from the lower to upper quartile ( $25^{\text {th }}$ to $75^{\text {th }}$ percentile). The middle line represents the median. A line extends from the minimum to the maximum value.

\section{Dynamic parameters to quantify the hemodynamic effects of VE}

At baseline, both $\Delta \mathrm{Vpeak}_{\text {brach }}$ and $\Delta \mathrm{PP}_{\text {rad }}$ were positively correlated with VE-induced change in $\mathrm{SVi}\left(\mathrm{r}^{2}=0.56\right.$ and $\mathrm{r}^{2}=$ $0.71 ; P<0.0001$, respectively). $\Delta \mathrm{SV}_{\text {Vigileo }}$ was also correlated, although less strongly $\left(r^{2}=0.32 ; P<0.001\right)$. Therefore, the greater the respiratory variation in brachial artery peak velocity, arterial pulse pressure or stroke volume, the greater the expected SVi increase after fluid administration. The VEinduced change in $\Delta \mathrm{Vpeak}_{\mathrm{brach}}$ and $\triangle \mathrm{PP}_{\text {rad }}$ were correlated with VE change in SVi $\left(r^{2}=0.58\right.$ and $r^{2}=0.56 ; P<0.0001$, respectively), although weakly for $\Delta \mathrm{SV}_{\text {Vigileo }}\left(\mathrm{r}^{2}=0.12, P<\right.$ $0.05)$. So a decrease in $\Delta \mathrm{Vpeak}_{\text {brach }}$ value after $\mathrm{VE}$ could be

\section{Figure 2}
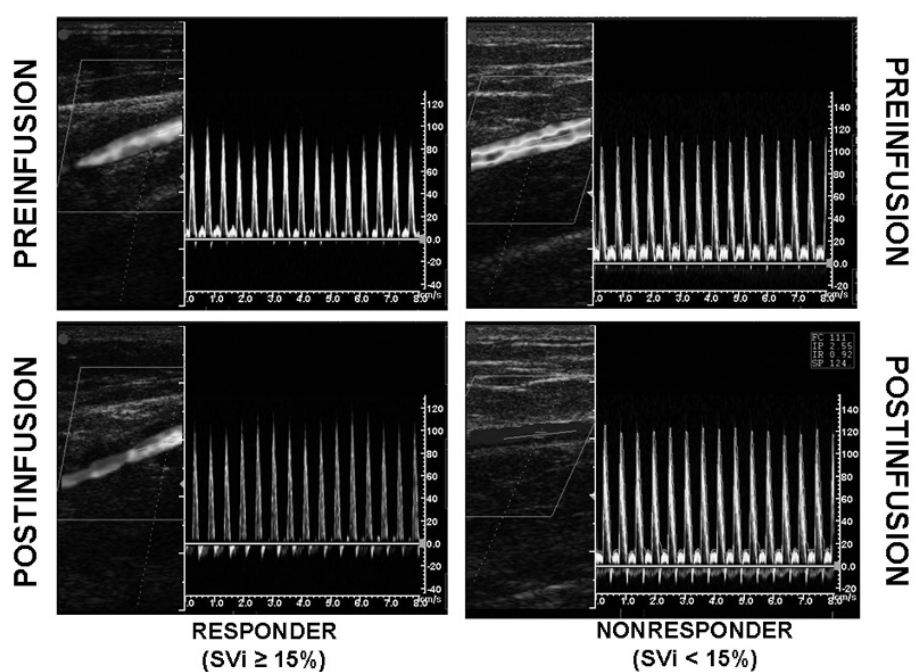

Illustrative example of Doppler evaluation of brachial artery peak velocity variation in a responder patient and nonresponder patient. In the responder

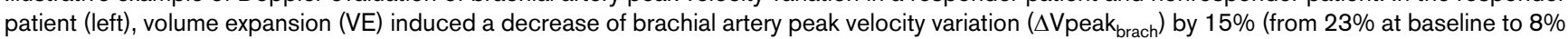
after VE) and an increase of stroke volume index and cardiac index by $27 \%$ and $12 \%$, respectively. Radial pulse pressure variation $(\Delta \mathrm{PP}$ rad $)$ and stroke volume variation $\left(\Delta S V_{\text {Vigileo }}\right.$ ) also significantly decreased in the same patient (from $23 \%$ to $4 \%$, and from $24 \%$ to $11 \%$, respectively). In nonre-

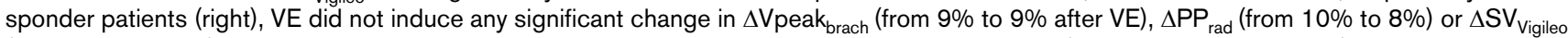
(from $13 \%$ to 12\%). Neither cardiac index nor stroke volume index increased significantly after VE (6\% and $8 \%$, respectively). SVi $=$ stroke volume index. 
Table 3

\begin{tabular}{|c|c|c|}
\hline & Pre VE & Post VE \\
\hline \multicolumn{3}{|l|}{$\Delta \mathrm{PP}_{\mathrm{rad}}, \%$} \\
\hline Responders & 18.29 (15.66 to 24.42$) \mathrm{t \dagger}$ & $8.58(4.59$ to 12.05$) \dagger^{* \star \star}$ \\
\hline Nonresponders & 4.74 (2.32 to 6.95$)$ & $3.15(0.96 \text { to } 5.24)^{\star}$ \\
\hline \multicolumn{3}{|l|}{$\Delta$ Vpeak $_{\text {brach }}, \%$} \\
\hline Responders & 13.94 (9.88 to 18.83$)+\dagger$ & $6.95(5.29 \text { to } 9.38)^{\star \star \star}$ \\
\hline Nonresponders & 7.76 (6.24 to 8.29$)$ & $5.52(4.38 \text { to } 7.66)^{\star}$ \\
\hline \multicolumn{3}{|l|}{$\Delta \mathbf{S V}_{\text {Vigileo }} \%$} \\
\hline Responders & 13 (11.75 to 21.17$)+\dagger$ & $9.33(7.08$ to 11.50$) \mathrm{t十}^{\star \star \star \star}$ \\
\hline Nonresponders & 7.67 (6.75 to 9.5$)$ & $5.67(4.67 \text { to } 6.59)^{\star \star}$ \\
\hline
\end{tabular}

Data are expressed as median with interquartile range $\left(25^{\text {th }}\right.$ to $75^{\text {th }}$ percentiles). ${ }^{*} P<0.05,{ }^{* *} P<0.001,{ }^{* * *} P<0.0001$ post VE vs pre VE. $+P$ $<0.001$, t† $P=0.0001$ responders vs nonresponders.

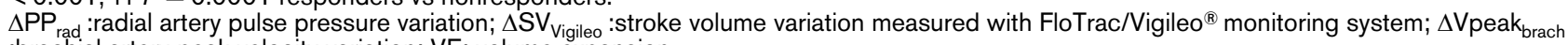
:brachial artery peak velocity variation; VE: volume expansion.

used to indicate a successful increase in stroke volume by fluid administration.

\section{Relationship between dynamic parameters of preload}

Before volume administration $\Delta$ Vpeak $_{\text {brach }}$ correlated with $\Delta \mathrm{PP}_{\text {rad }}\left(\mathrm{r}^{2}=0.82 ; P<0.0001\right)$ and $\Delta \mathrm{SV}_{\text {Vigileo }}\left(\mathrm{r}^{2}=0.47 ; P<\right.$ $0.0001)$. At baseline, $\Delta \mathrm{PP}_{\text {rad }}$ also correlated with $\Delta S V_{\text {Vigileo }}\left(r^{2}\right.$ $=0.59 ; P<0.0001)$. The VE-induced decreases in $\Delta$ Vpeak-

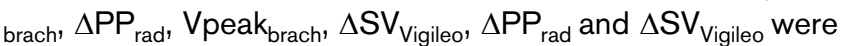
also significantly correlated $\left(\mathrm{r}^{2}=0.71 ; P<0.0001, \mathrm{r}^{2}=0.26\right.$; $P<0.01$ and $\mathrm{r}^{2}=0.39 ; P<0.0001 ;$ respectively).

\section{Prediction of fluid responsiveness}

The area under the ROC curves for baseline $\Delta \mathrm{Vpeak}_{\text {brach }}(0.88$ $\pm 0.06 ; 95 \% \mathrm{Cl} 0.74$ to 0.96$), \Delta \mathrm{PP}_{\mathrm{rad}}(0.97 \pm 0.03 ; 95 \% \mathrm{Cl}$ 0.86 to 0.99$)$ and $\Delta \mathrm{SV}_{\text {Vigileo }}(0.89 \pm 0.06 ; 95 \% \mathrm{Cl} 0.75$ to 0.97) was not significantly different (Figure 3). All dynamic parameters of preload were better predictors of fluid responsiveness than CVP (area under the curve: $0.64 \pm 0.09 ; 95 \%$ $\mathrm{Cl} 0.47$ to 0.79 ). A $\Delta$ Vpeak $_{\text {brach }}$ value of more than $10 \%$ predicted fluid responsiveness with a sensitivity of $74 \%(95 \% \mathrm{Cl}$ 49 to $91 \%$ ) and a specificity of 95\% (95\% Cl 74 to $99 \%$ ), with positive and negative predictive values of $93 \%$ and $78 \%$, respectively. $A \Delta \mathrm{PP}_{\text {rad }}$ value of more than $10 \%$ and a $\Delta S V_{\text {Vigileo }}$ of more than $11 \%$ predicted volume responsiveness with a sensitivity of $95 \%$ (95\% Cl 74 to $99 \%)$ and $79 \%$ (95\% Cl 54 to $94 \%$ ), and a specificity of $95 \%(95 \% \mathrm{Cl} 74$ to $99 \%)$ and $89 \%$ (95\% Cl 67 to 97\%), respectively.

\section{Discussion}

This study demonstrates that Doppler evaluation of the $\Delta \mathrm{Vpeak}_{\text {brach }}$ efficiently predicts the hemodynamic response to

\section{Figure 3}

\section{$\Delta$ Vpeak $_{\text {brach }}, \Delta \mathrm{PP}_{\text {rad }}, \Delta \mathrm{SV}_{\text {Vigileo }}$ and CVP comparison ROC curves}

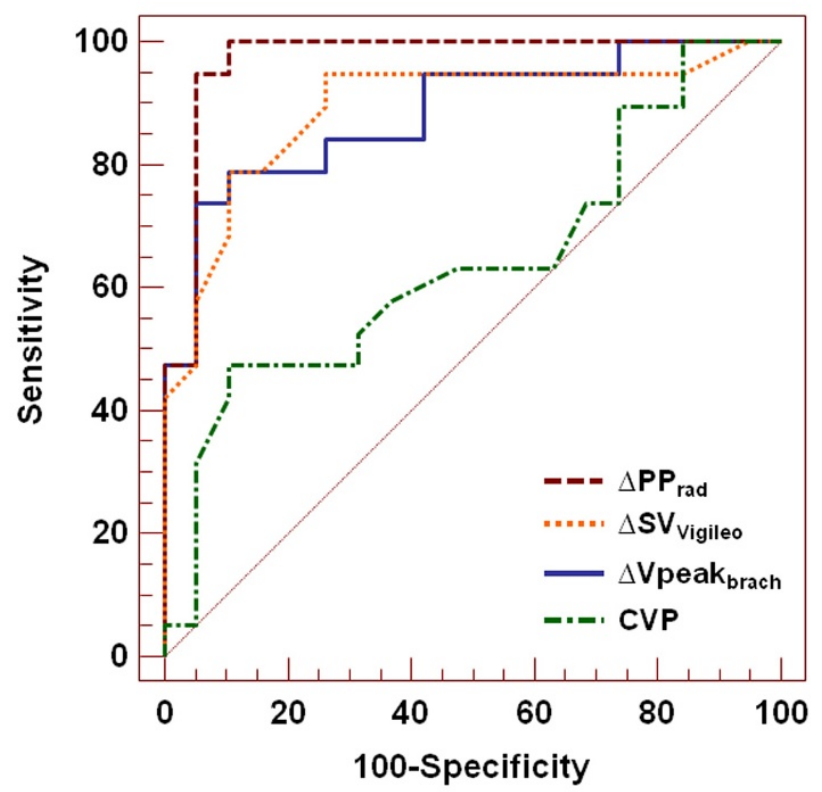

Comparison of receiver operating characteristics curves to discriminate fluid expansion responders and nonresponders. Area under the receiver operator curve $(\mathrm{ROC})$ for respiratory variations of brachial peak velocity $\left(\Delta V_{\text {peak }}\right.$ brach $)$ was 0.88 , for radial arterial pulse pressure variation $\left(\Delta \mathrm{PP}_{\mathrm{rad}}\right)$ it was 0.97 , for stroke volume variation measured using the FloTrac/Vigileo monitoring system $\left(\Delta S V_{\text {Vigileo }}\right)$ it was 0.89 and for central venous pressure (CVP) it was 0.64 . 
volume expansion in mechanically ventilated patients with acute circulatory failure.

Dynamic assessment of fluid responsiveness, unlike absolute measurements of preload, is based on the principle that challenging the cardiovascular system to a reversible and transient change on preload, the magnitude of the induced variations in stroke volume or its surrogates are proportional to the preloaddependence status of a patient [12]. Swings in intrathoracic pressure during mechanical ventilation modulate LV stroke volume by cyclically varying RV preload. As the main mechanism for reducing RV stroke volume (and hence LV filling) is impeding pressure gradient for venous return and RV preload [13], the increase in intrathoracic pressure will transiently reduce LV stroke output only if both the ventricles are operating in the steep part of the Frank-Starling curve. Therefore, phasic variations of LV stroke volume induced by positive-pressure ventilation could be used as an indicator of biventricular preload responsiveness in mechanically ventilated patients [14].

As direct measurement of LV stroke volume remains a complicated task at the bedside, different surrogate parameters have been proposed to assess the effects of mechanical ventilation in LV stroke volume for predicting volume responsiveness. In this regard respiratory variations on arterial pulse pressure [10] or the pulse contour-derived stroke volume variation $[5,15]$ have been repeatedly demonstrated to accurately predict fluid responsiveness in different settings and clinical situations [4].

With echocardiography becoming more widely available in intensive care units and increasingly used in the management of hemodynamically unstable patients, the noninvasive assessment of preload dependence has logically aroused the interest of some authors. Feissel and colleagues [16] demonstrated that respiratory variations of aortic blood velocity, measured by transesophageal echocardiography at the level of the aortic annulus, was a more reliable parameter than a static index of preload such as LV end-diastolic area for predicting the hemodynamic response to VE in patients with septic shock. Similarly, Monnet and colleagues [6], measuring the descending aortic blood flow with an esophageal Doppler probe, reported that aortic blood flow variation and respiratory variation in aortic peak velocity were reliable indices for detecting fluid responsiveness and better predictors than the flow time corrected for heart rate, a static preload index provided by the esophageal Doppler. Moreover, in children receiving mechanical ventilation, Durand and colleagues [17], confirmed that the respiratory variation in aortic peak velocity measured by transthoracic pulsed-Doppler was superior to pulse pressure variation and systolic pressure variation for assessing cardiac preload reserve. Additionally, in two experimental studies, Slama and colleagues $[18,19]$ analyzed the effects of controlled blood withdrawal and restitution in mechanically ventilated rabbits on the aortic velocity time integral, registered by tran- sthoracic echocardiography, and the aortic blood flow velocity, recorded by esophageal Doppler. They observed that the prediction of hemodynamic consequences of blood depletion and restoration was highly accurate in both methods.

Recently, Brennan and colleagues [7] suggested that Doppler evaluation of respiratory variations in peak velocity of brachial artery blood flow, assessed by internal medicine residents after a brief training in brachial Doppler measurement, could be used as an easily obtainable, noninvasive surrogate of pulse pressure variation, reporting a close correlation and a high level of agreement between $\Delta \mathrm{Vpeak}_{\text {brach }}$ and $\Delta \mathrm{PP}_{\text {rad. }}$. Using a $\Delta \mathrm{PP}_{\text {rad }}$ cutoff of $13 \%$ to define a positive prediction of fluid responsiveness, a $\Delta \mathrm{Vpeak}_{\text {brach }}$ value of $16 \%$ or more allowed predicting with a $91 \%$ of sensitivity and $95 \%$ of specificity. Regrettably, the authors did not confirm their findings against an objective end-point of fluid responsiveness, such as changes in stroke volume or $\mathrm{CO}$ after a volume challenge.

Our results confirm the ability of $\Delta \mathrm{Vpeak}_{\text {brach }}$ to detect preload dependence in patients receiving passive mechanical ventilation and are consistent with previously published studies by demonstrating the efficiency of dynamic parameters for predicting fluid responsiveness and its superiority over static indicators of cardiac preload. Unlike invasive indices of preload dependence, $\Delta \mathrm{V}_{\text {peak }} \mathrm{k}_{\text {brach }}$ measurement does not need arterial catheterization, is quickly performed at the bedside and does not require any special device or $\mathrm{CO}$ monitoring tool, just widely available ultrasound equipment and a minimal training in Doppler acquisition to obtain reliable measurements. Therefore, the noninvasive evaluation of mechanical ventilation over peripheral blood flow could be used as a first-line approach in the emergency department or as an initial intensive care unit assessment in hemodynamically unstable patients for whom fluid administration is considered.

When interpreting the results presented in this study some limitations must be considered. First, brachial arterial flow seems to be quite sensitive to the mechanical influence of active muscle contraction [20]. Because neuromuscular blockade was not used in all patients we cannot exclude the influence of this factor in brachial artery blood velocity measurements. However, no patient showed any spontaneous effort during the study, so the sedation level in these patients was probably deep enough to discard this possibility. Secondly, we used the FloTrac/Vigileo system for CO measurements, an uncalibrated monitoring device based on the arterial pulse contour analysis without the need for external calibration. Although the accuracy of this system has been questioned in some studies $[21,22]$, recent papers have cited a good agreement with the thermodilution technique $[23,24]$. Moreover, the ability to track $\mathrm{CO}$ and stroke volume changes following VE seems to be comparable with the pulmonary artery catheter or the aortic Doppler-echocardiography, allowing a comparable characterization of patients according to their response to volume 
administration [25]. Thirdly, all surrogate parameters of LV stroke volume variations fail to predict fluid responsiveness during spontaneous ventilation or in the presence of cardiac arrhythmias [26], so our results should not be extrapolated to these clinical conditions.

\section{Conclusions}

In conclusion, this study provides additional evidence of the utility of respiratory variations in brachial artery peak velocity induced by intermittent positive-pressure ventilation as a feasible tool for predicting fluid responsiveness, with efficiency similar to other well-known dynamic parameters of preload, in mechanically ventilated patients with acute circulatory failure.

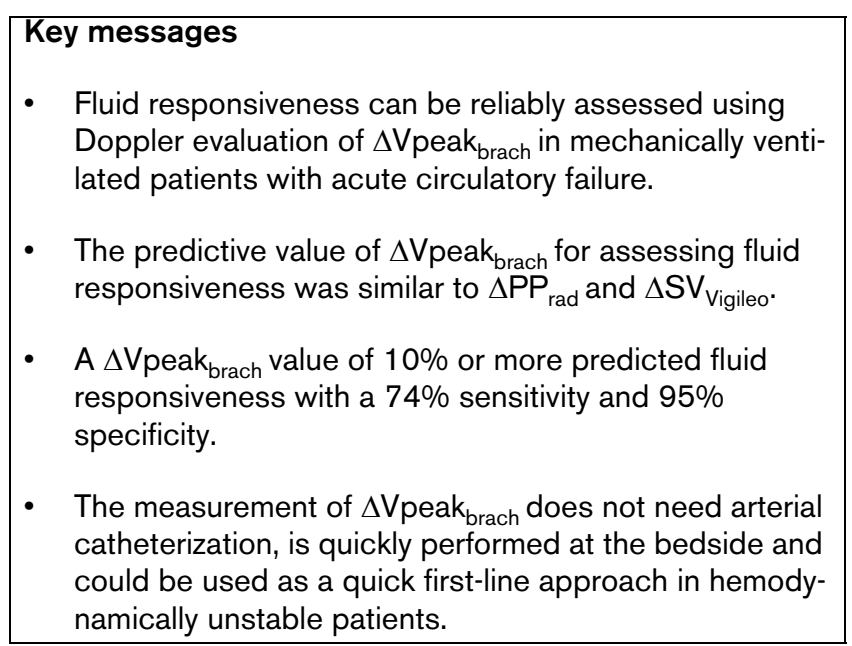

\section{Competing interests}

MIMG has received consulting fees from Edwards Lifesciences. AGC and JCDM have no conflicts of interest to disclose.

\section{Authors' contributions}

MIMG conceived and designed the study, performed the statistical analysis, participated in the recruitment of patients and drafted the manuscript. AGC and JCDM participated in the study design, patient recruitment, measurements and data collection and helped draft the manuscript. All the authors read and approved the final manuscript.

\section{References}

1. Michard F, Teboul JL: Predicting fluid responsiveness in ICU patients: a critical analysis of the evidence. Chest 2002, 121:2000-2008.

2. Bendjelid K, Romand JA: Fluid responsiveness in mechanically ventilated patients: a review of indices used in intensive care. Intensive Care Med 2003, 29:352-360.

3. Michard F, Teboul JL: Using heart-lung interactions to assess fluid responsiveness during mechanical ventilation. Crit Care 2000, 4:282-289.

4. Michard F: Changes in arterial pressure during mechanical ventilation. Anesthesiology 2005, 103:419-428.

5. Hofer CK, Senn A, Weibel L, Zollinger A: Assessment of stroke volume variation for prediction of fluid responsiveness using the modified FloTrac and PiCCOplus system. Crit Care 2008, 12:R82.
6. Monnet X, Rienzo M, Osman D, Anguel N, Richard C, Pinsky MR, Teboul JL: Esophageal Doppler monitoring predicts fluid responsiveness in critically ill ventilated patients. Intensive Care Med 2005, 31:1195-1201

7. Brennan JM, Blair JE, Hampole C, Goonewardena S, Vasaiwala S, Shah D, Spencer KT, Schmidt GA: Radial artery pulse pressure variation correlates with brachial artery peak velocity variation in ventilated subjects when measured by internal medicine residents using hand-carried ultrasound devices. Chest 2007, 131:1301-1307.

8. Eikermann M, Magder S, Malhotra A: Is brachial artery peak velocity variation ready for prime time? Chest 2007, 131:1279-1281.

9. OtiPlot - Data Analysis and Scientific Plotting [http://soft.proin dependent.com/qtiplot.html]

10. Michard F, Boussat S, Chemla D, Anguel N, Mercat A, Lecarpentier Y, Richard C, Pinsky MR, Teboul JL: Relation between respiratory changes in arterial pulse pressure and fluid responsiveness in septic patients with acute circulatory failure. Am J Respir Crit Care Med 2000, 162:134-138.

11. Manecke GR: Edwards FloTrac sensor and Vigileo monitor: easy, accurate, reliable cardiac output assessment using the arterial pulse wave. Expert Rev Med Devices 2005, 2:523-527.

12. Pinsky MR, Teboul JL: Assessment of indices of preload and volume responsiveness. Curr Opin Crit Care 2005, 11:235-239.

13. Pinsky MR: The hemodynamic consequences of mechanical ventilation: an evolving story. Intensive Care Med 1997, 23:493-503.

14. Magder S: Clinical usefulness of respiratory variations in arterial pressure. Am J Respir Crit Care Med 2004, 169:151-155.

15. Cannesson M, Musard H, Desebbe O, Boucau C, Simon R, Henaine $\mathrm{R}$, Lehot JJ: The ability of stroke volume variations obtained with Vigileo/FloTrac system to monitor fluid responsiveness in mechanically ventilated patients. Anesth Analg 2009, 108:513-517.

16. Feissel M, Michard F, Mangin I, Ruyer O, Faller JP, Teboul JL: Respiratory changes in aortic blood velocity as an indicator of fluid responsiveness in ventilated patients with septic shock. Chest 2001, 119:867-873.

17. Durand P, Chevret L, Essouri S, Haas V, Devictor D: Respiratory variations in aortic blood flow predict fluid responsiveness in ventilated children. Intensive Care Med 2008, 34:888-894.

18. Slama M, Masson H, Teboul JL, Arnould ML, Nait-Kaoudjt R, Colas B, Peltier M, Tribouilloy C, Susic D, Frohlich E, Andréjack M: Monitoring of respiratory variations of aortic blood flow velocity using esophageal Doppler. Intensive Care Med 2004, 30:1182-1187.

19. Slama M, Masson H, Teboul JL, Arnout ML, Susic D, Frohlich E, Andrejak M: Respiratory variations of aortic VTI: a new index of hypovolemia and fluid responsiveness. Am J Physiol Heart Circ Physiol 2002, 283:H1729-1733.

20. Gault JH, Ross J Jr, Mason DT: Patterns of brachial arterial blood flow in conscious human subjects with and without cardiac dysfunction. Circulation 1966, 34:833-848.

21. Mayer J, Boldt J, Schollhorn T, Rohm KD, Mengistu AM, Suttner S: Semi-invasive monitoring of cardiac output by a new device using arterial pressure waveform analysis: a comparison with intermittent pulmonary artery thermodilution in patients undergoing cardiac surgery. Br J Anaesth 2007, 98:176-182.

22. Sander M, Spies C, Grubitzsch H, Foer A, Muller M, von Heymann C: Comparison of uncalibrated arterial waveform analysis in cardiac surgery patients with thermodilution cardiac output measurements. Critical Care 2006, 10:R164.

23. Mayer J, Boldt J, Wolf MW, Lang J, Suttner S: Cardiac output derived from arterial pressure waveform analysis in patients undergoing cardiac surgery: validity of a second generation device. Anesth Analg 2008, 106:867-872.

24. Senn A, Button D, Zollinger A, Hofer CK: Assessment of cardiac output changes using a modified FloTrac/Vigileo algorithm in cardiac surgery patients. Crit Care 2009, 13:R32.

25. Biais M, Nouette-Gaulain K, Cottenceau V, Revel P, Sztark F: Uncalibrated pulse contour-derived stroke volume variation predicts fluid responsiveness in mechanically ventilated patients undergoing liver transplantation. $\mathrm{Br} J$ Anaesth 2008, 101:761-768. 
26. Michard F: Volume management using dynamic parameters: the good, the bad, and the ugly. Chest 2005, 128:1902-1903. 